By: Paul J. Silvia and Shelley T. Duval

Silvia, P. J., \& Duval, T. S. (2001). Objective self-awareness theory: Recent progress and enduring problems. Personality and Social Psychology Review, 5, 230-241.

Made available courtesy of SAGE Publications (UK and US): http://psr.sagepub.com/

****Note: Figures may be missing from this format of the document

\begin{abstract}
:
Objective self-awareness theory has undergone fundamental changes in the 3 decades since Duval and Wicklund's (1972) original formulation. We review new evidence that bears on the basic tenets of the theory. Many of the assumptions of self-awareness theory require revision, particularly how expectancies influence approach and avoidance of self-standard discrepancies; the nature of standards, especially when they are changed; and the role of causal attribution in directing discrepancy reduction. However, several unresolved conceptual issues remain; future theoretical and empirical directions are discussed.
\end{abstract}

\title{
Article:
}

The human dilemma is that which arises out of a man's capacity to experience himself as both subject and object at the same time. Both are necessary--for the science of psychology, for therapy, and for gratifying living. (May, 1967, p. 8)

Although psychological perspectives on the self have a long history (e.g., Cooley, 1902; James, 1890; Mead, 1934), experimental research on the self has emerged only within the last 40 years. One of the earliest "self theories" was objective self-awareness (OSA) theory (Duval \& Wicklund, 1972). OSA theory was concerned with the self-reflexive quality of the consciousness. Just as people can apprehend the existence of environmental stimuli, they can be aware of their own existence: "When attention is directed inward and the individual's consciousness is focused on himself, he is the object of his own consciousness--hence 'objective' self awareness" (Duval \& Wicklund, 1972, p. 2). This is contrasted with "subjective self-awareness" that results when attention is directed away from the self and the person "experiences himself as the source of perception and action" (Duval \& Wicklund, 1972, p. 3). By this, Duval and Wicklund (1972,chap. 3) meant consciousness of one's existence on an organismic level, in which such existence is undifferentiated as a separate and distinct object in the world.

OSA theory has stimulated a lot of research and informed basic issues in social psychology, such as emotion (Scheier \& Carver, 1977), attribution (Duval \& Wicklund, 1973), attitude--behavior consistency (Gibbons, 1983), self-standard comparison (Duval \& Lalwani, 1999), prosocial behavior (Froming, Nasby, \& McManus, 1998), deindividuation (Diener, 1979), stereotyping (Macrae, Bodenhausen, \& Milne, 1998), self-assessment (Silvia \& Gendolla, in press), terror management (Arndt, Greenberg, Simon, Pyszczynski, \& Solomon, 1998; Silvia, 2001), and group dynamics (Duval, 1976; Mullen, 1983). Self-focused attention is also fundamental to a host of clinical and health phenomena (Hull, 1981; Ingram, 1990; Pyszczynski, Hamilton, Greenberg, \& Becker, 1991; Wells \& Matthews, 1994).

The study of self-focused attention continues to be a dynamic and active research area. A lot of research relevant to basic theoretical issues has been conducted since the last maj or review (Gibbons, 1990). Recent research has made progress in understanding links between self-awareness and causal attribution, the effects of expectancies on self-standard discrepancy reduction, and the nature of standards--the dynamics of selfawareness are now viewed quite differently. We review these recent developments[1] and hope that a conceptual integration of new findings will further stimulate research on self-focused attention. However, there 
is still much conceptual work left to be done, and many basic issues remain murky and controversial. We discuss these unresolved issues and sketch the beginnings of some possible solutions.

\section{Original Theory}

The original statement of OSA theory (Duval \& Wicklund, 1972) employed only a few constructs, relations, and processes. The theory assumed that the orientation of conscious attention was the essence of selfevaluation. Focusing attention on the self brought about objective self-awareness, which initiated an automatic comparison of the self against standards. The self was defined very broadly as the person's knowledge of the person. A standard was "defined as a mental representation of correct behavior, attitudes, and traits ... All of the standards of correctness taken together define what a 'correct' person is" (Duval \& Wicklund, 1972, pp. 3, 4).

This simple system consisting of self, standards, and attentional focus was assumed to operate according to gestalt consistency principles (Heider, 1960). If a discrepancy was found between self and standards, negative affect was said to arise. This aversive state then motivated the restoration of consistency. Two behavioral routes were proposed. People could either actively change their actions, attitudes, or traits to be more congruent with the representations of the standard or could avoid the self-focusing stimuli and circumstances. Avoidance effectively terminates the comparison process and hence all self-evaluation. Early research found solid support for these basic ideas (Carver, 1975; Gibbons \& Wicklund, 1976; Wicklund \& Duval, 1971). Duval and Wicklund (1972) also assumed that objective self-awareness would generally be an aversive state--the probability that at least one self-standard discrepancy exists is quite high. This was the first assumption to be revised. Later work found that self-awareness can be a positive state when people are congruent with their standards (Greenberg \& Musham, 1981; Ickes, Wicklund, \& Ferris, 1973).

\section{New Developments}

OSA theory has grown considerably from the original statement (Duval \& Wicklund, 1972). Our review focuses primarily on core theoretical developments since the last review (Gibbons, 1990). Other interesting aspects, such as interpersonal processes and interoceptive accuracy, have not changed significantly since previous reviews (Gibbons, 1990; Silvia \& Gendolla, in press). We will also overlook the many clinical consequences of self-awareness; these have been exhaustively reviewed elsewhere (Pyszczynski et al., 1991; Wells \& Matthews, 1994).

\section{Expectancies and Avoiding Self-Awareness}

Reducing a discrepancy or avoiding self-focus are equally effective ways of reducing the negative affect resulting from a discrepancy. When do people do one or the other? The original theory was not very specific about when approach versus avoidance would occur. Duval and Wicklund (1972) did, however, speculate that two factors should be relevant. The first was whether people felt they could effectively reduce the discrepancy; the second was whether the discrepancy was small or large.

In their translation of OSA theory into a "test--operate--test--exit" (TOTE) feedback system, Carver, Blaney, and Scheier (1979a, 1979b) suggested that expectancies regarding outcome favorability determine approach versus avoidance behavior. When a self-standard discrepancy is recognized, people implicitly appraise their likelihood of reducing the discrepancy (cf. Bandura, 1977; Lazarus, 1966). If eventual discrepancy reduction is perceived as likely, people will try to achieve the standard. When expectations regarding improvement are unfavorable, however, people will try to avoid self-focus.

Later research and theory (Duval, Duval, \& Mulilis, 1992) refined Duval and Wicklund's (1972) speculations and the notion of outcome favorability. Expectancies are not simply and dichotomously favorable or unfavorable--they connote a person's rate of progress in discrepancy reduction relative to the magnitude of the discrepancy. More specifically, people will try to reduce a discrepancy to the extent they believe that their rate of progress is sufficient relative to the magnitude of the problem. Those who believe their rate of progress to be insufficient will avoid. 
To test this hypothesis, participants were told they were either highly (90\%) or mildly (10\%) discrepant from an experimental standard (Duval et al., 1992, Study 1). Participants were then given the opportunity to engage in a remedial task that was guaranteed by the experimenter to totally eliminate their deficiency provided that they worked on the task for $2 \mathrm{hr}$ and $10 \mathrm{~min}$. However, the rate at which working on the task would reduce the discrepancy was varied. In the low rate of progress conditions individuals were shown a performance curve indicating no progress until the last 20 min of working on the remedial task. During the last 20 min discrepancy was reduced to zero. In the constant rate of progress condition, participants were shown a performance curve in which progress toward discrepancy reduction began immediately and continued throughout such efforts with $30 \%$ of the deficiency being reduced in the first $30 \mathrm{~min}$ of activity and totally eliminated after $2 \mathrm{hr}$ and $10 \mathrm{~min}$.

Results indicated that persons who believed the discrepancy to be mild and progress to be constant worked on the remedial task; those who perceived the problem to be mild but the rate of progress to be low avoided this activity. However, participants who thought that the discrepancy was substantial and the rate of progress only constant avoided working on the remedial task relative to those in the mild discrepancy and constant rate of progress condition. These results were conceptually replicated in a second experiment (Duval et al., 1992) using participants' time to complete the total $2 \mathrm{hr}$ and $10 \mathrm{~min}$ of remedial work as the dependent measure. This pattern suggests that the rate of progress was sufficient relative to the magnitude of the discrepancy in the mild discrepancy and constant rate of progress condition; this in turn promoted approaching the problem. In the high discrepancy and constant rate of progress condition and the high and mild discrepancy and low rate of progress conditions, rate of progress was insufficient and promoted avoiding the problem.

In a third experiment (Duval et al., 1992), people were again led to believe that they were either highly or mildly discrepant from a standard on an intellectual dimension and then given the opportunity to reduce that deficiency by working on a remedial task. As in Experiments 1 and 2, approximately half of the participants were led to believe that rate of progress would be constant. However, in this study the other half of the participants were shown a performance curve indicating accelerated self-standard discrepancy reduction--nearly $75 \%$ of the deficiency would be reduced during the first 30 min of work on the remedial task. As predicted, individuals in the accelerated and constant rate of progress conditions spent a substantial amount of time working on the remedial task when they believed the deficiency to be mild. More important, persons who believed that the discrepancy was large but rate of progress to be accelerated persisted on the remedial task, whereas those who perceived the problem to be large but rate of progress only constant again, as in Experiments 1 and 2, avoided. Furthermore, and as expected, these results were obtained only when self-focus was high. Avoidance, then, occurs when self-focused people perceive an insufficient rate of progress in reducing a discrepancy of given magnitude. When rate of progress is sufficient relative to the magnitude of self-standard discrepancy, people will take action rather than avoid.

\section{Attributions for Self-Relevant Events}

Early self-awareness research showed that heightened self-focus had a main effect on attributions--self-focused people saw themselves as more responsible for both positive and negative events (Duval \& Wicklund, 1973). Subsequent research, however, found that high self-awareness promoted defensive, external attributions for negative events (Cohen, Dowling, Bishop, \& Maney, 1985; Federoff \& Harvey, 1976), presumably because people wanted to avoid the amplified experienced of failure (Ickes et al., 1973). Yet self-awareness clearly cannot always lead to self-serving failure attributions. If people never took responsibility for a discrepancy, they would never change or improve the self (Duval \& Lalwani, 1999). Many studies show that people will, if possible, try to change the self to reduce a discrepancy (Duval et al., 1992; McDonald, 1980), so there must be instances in which highly self-focused people are attributing failure to self.

Duval and Duval $(1983,1987)$ suggested that the answer lies in the intersection of the self-to-standard comparison system and the causal attribution system. The self-to-standard comparison system, conceived as a goal-directed system with a preferred state (Rudner, 1966), prefers the state in which self and standards are identical. Yet the attribution system, also conceived as goal directed (Duval \& Duval, 1983), prefers the state in 
which effects are connected with their most plausible causes (Heider, 1944, 1958). The interplay of these two motives determines whether success and failure are attributed to self or to an external possible cause.

\section{Success Attributions}

The motives of the systems are harmonious when self is the most plausible cause for success. Attributing success to self would achieve self-standard congruity as well as connect success with the most plausible cause. In this case, an attribution to self should be amplified because the attribution simultaneously furthers the goals of both systems. An experiment supports this hypothesis (Duval \& Silvia, in press, Study 3). Participants worked on an ambiguous task under high or low self-focus conditions and received success feedback. Highly self-focused participants attributed more causality for success to self and consequently had higher state selfesteem compared to participants low in self-focus.

\section{Failure Attributions}

However, the two systems can also be in conflict. When self is the most plausible cause for failure, an internal attribution would thwart the self-to-standard comparison system but satisfy the attribution system. Conversely, an external attribution would maintain self-standard congruity but thwart the attribution system. What determines failure attributions when the systems conflict? One critical moderator is the likelihood that failure can be improved in the future. If people can rapidly remedy their failure, the costs of an internal attribution to the self-to-standard comparison system are fairly low--a discrepancy will be created, but it can be quickly reduced. If people do not expect rapid improvement, however, an internal attribution would create an irreducible discrepancy. In this situation the costs of an inaccurate attribution are smaller than the costs of an irreducible discrepancy; an external attribution should thus be made (Duval \& Duval, 1987).

Many experiments have found that self-awareness and likelihood of improvement interact to determine failure attributions (Duval \& Duval, 1983, 1987; Duval \& Silvia, in press; Silvia \& Duval, in press). Participants high and low in self-focus were told they had failed a task. Half were told they had the capacity to quickly improve in the future, and the other half were told that the prospects for future improvement were bleak. As expected, highly self-focused people attributed failure to self when they felt they could improve; failure was attributed externally when improvement was perceived as unlikely. Furthermore, state self-esteem decreased when failure was attributed to self but remained unchanged when failure was externalized (Duval \& Silvia, in press, Studies 2 and 3). Probability of improvement had no effects when self-focus was low, indicating that the operation of both systems is necessary. External attributions were also directed to negative external targets instead of positive external targets (Silvia \& Duval, in press), as suggested by Heider's (1958) analysis of balance theory and attribution.

\section{Summary}

A more detailed picture of the links between self-awareness, attribution, and action now emerges. When people are discrepant from a standard, they make attributions for the cause of the discrepancy and appraise the likelihood that the discrepancy could be rapidly reduced. If the discrepancy can be reduced, people will attribute failure internally and attempt to change self. If the discrepancy cannot be reduced, people will attribute failure externally to a similar possible cause, such as a standard or another person. This will promote attempts to avoid self-awareness and reminders of the discrepancy between self and standards.

\section{Changing Self or Changing Standards}

OSA theory originally assumed that people will reduce discrepancies by changing self to match standards. This was based on "least effort" notions prominent in consistency theories (Heider, 1958). Because thoughts and behaviors were presumably easier to change than standards, people would act on the self instead of standards. The characterization of standards of correctness as firmly internalized representations of what one should do also implied that standards were resistant to change. This was also incorporated into Carver and Scheier's (1981) cybernetic model. Standards were viewed as reference values in a TOTE system. Classical TOTE models (Miller, Galantner, \& Pribram, 1960) view standards as invariant elements, which implies that self must 
be changed toward the standard. Although both theories briefly speculate about how reference values might be modified (Carver \& Scheier, 1981; Miller et al., 1960), this process is not a major part of either theory.

The effect of self-awareness on attempts to meet standards is the "bread and butter" effect of OSA theory--it has been demonstrated in over a hundred experiments (e.g., Carver, 1975; Gibbons, 1978). Recent research, however, has suggested that people will also change their standards to be consistent with the self. OSA theory assumes that the preferred state of the self-to-standard comparison system is consistency between self and standards. Like other consistency theories (e.g., Heider, 1958), it does not matter what cognitive element is changed so long as the goal state of cognitive consistency is achieved. Changing self or changing standards, then, should be equally effective ways of restoring self-standard congruity.

When will people change standards? Dana, Lalwani, and Duval (1997) suggested that this will occur when people focus attention on the standard. When people are discrepant, focusing on the standard should lead to a negative evaluation of the standard. This in turn should lead to a change in the standard toward self instead of attempts to change self toward the standard. Two experiments supported these hypotheses. Participants worked on a prose copying task under high or low self-focus conditions and were told they had failed to meet the experimental performance standard. Half were then led to focus their attention on the experimental standard, whereas the other half focused attention on their performance. When highly self-focused people focused on the standard, they (a) evaluated it more negatively, (b) changed the standard to match their performance, and (c) did not try to improve their performance on a second trial. Highly self-focused people who focused on their performance, in contrast, did not derogate or change the standard and worked hard to meet the standard in the second trial. As expected, there were no effects when self-awareness was low.

\section{Attribution and Changing Standards}

Yet why does attentional focus have these effects? Duval and Lalwani (1999) proposed that causal attribution is the mechanism that determines whether self or standards will be changed. Attentional focus partially determines causal attributions (Arkin \& Duval, 1975; Duval \& Duval, 1983; Pryor \& Kriss, 1977; Taylor \& Fiske, 1978), so focusing on the standard leads people to attribute the cause of the discrepancy to the standard. When attention is focused on their own performance, however, people attribute causality for the discrepancy to self. People will naturally try to act on their perceived cause of their discrepancy (Heider, 1958). If self is seen as causal, people will change self; if standards are seen as causal, people will change standards.

An experiment tested these hypotheses (Duval \& Lalwani, 1999). Participants worked on a prose-copying task under conditions of high or low self-awareness; all persons were told they performed below the standard of the study. The experimenter then diverted attention to performance or to the standard by reiterating the person's score or reiterating the standard, respectively. After working on the prose task a second time, participants completed measures of attribution, desire to change the standard, and whether they would raise or lower the standard. As expected, people attributed failure to self when they focused on their performance. This led to attempts to meet the standard on the second trial. Focusing on the standard, in contrast, led to an attribution of failure to the standard. This led to a desire to change the standard, an actual change in the standard toward the self, and no attempt to meet the standard in the second trial. These effects were only found when self-awareness was high. This study thus nicely demonstrates the link between causal attribution and attempted discrepancy reduction.

\section{Changing Moral Standards}

Additional evidence for changing standards toward oneself comes from research on "moral hypocrisy" (Batson, Kobrynowicz, Dinnerstein, Kampf, \& Wilson, 1997), which is the "motivation to appear moral while, if possible, avoiding the cost of actually being moral" (Batson, Thompson, Seuferling, Whitney, \& Strongman, 1999, p. 526). Moral hypocrisy is typically demonstrated by asking participants to allocate a positive reward to themselves or another (fictional) person. Participants will often flip a coin, but $90 \%$ of the time the coin "randomly" allocates the positive outcome to the participant (Batson et al., 1997). Such a strategy enables the person to appear moral without incurring the cost of actual morality. 
Batson et al. (1999,Study 3) asked participants to decide to assign themselves or another participant to work on a positive or neutral task. Self-awareness was manipulated with the presence or absence of a mirror. A moral standard was made salient for half the participants, who were told "most participants feel that giving the other person the positive consequences task is the most morally right way to assign themselves and the other participant to the tasks" (p. 532). The other half did not receive a salient moral standard. When the standard was salient, high self-awareness increased the proportion who assigned the other to the positive task, thus replicating the classic OSA effect. When there was no salient moral standard, however, none of the highly self-aware participants assigned the other to the positive task. Yet this presumably contradicted their own standards concerning morality and fairness: How did they reduce the discrepancy? Measures of the "most morally right way to assign the task" revealed that these participants changed their moral standards to be congruent with their actions. Nearly $92 \%$ of the high self-awareness and salient standard persons said that the other-benefitting decision was most moral--only $25 \%$ of the high self-awareness and no salient standard persons said this.

These studies might at first appear contradictory--the prose-copying study found that a salient standard led to standard changing, whereas the moral hypocrisy study found that an absence of a salient standard led to standard changing. The key difference is that in the prose-copying study attention was directed to the standard immediately following failure feedback. This conjoined the aversive failure experience and the standard (Pryor \& Kriss, 1977; Taylor \& Fiske, 1978) and thus promoted attribution to the standard (Duval \& Duval, 1983). In the moral hypocrisy study, the standard was emphasized before people made their moral decisions and had the possibility to fail. When it was emphasized beforehand, people adhered to it; when it was not emphasized, people followed the "tilt" built into the procedure and acted unfairly and then later reconciled their acts and ideals. These studies are thus consistent and indeed offer support for very different facets of the phenomenon. The prose study explores standard changing using a deliberate manipulation of attribution; the morality study shows that shifts in standards will occur spontaneously without prompting.

\section{Summary}

Although changing standards is not explicitly predicted by earlier formulations of self-awareness theory (Carver \& Scheier, 1981; Duval \& Wicklund, 1972; Gibbons, 1990; Wicklund, 1975), it is entirely consistent with the core assumption of OSA theory of a self-standard consistency system. Attributing the cause of the discrepancy to self or the standard appears to determine whether self or standards is changed and whether action is taken to reduce the discrepancy (Dana et al., 1997; Duval \& Lalwani, 1999). The moral hypocrisy study (Batson et al., 1999) offers converging support for this view. This study demonstrates the effect with a personal (rather than experimental) standard and extends the effect beyond task performance into moral decision making.

Why have researchers not observed this effect earlier? One factor mentioned previously is that early conceptions of standards as standards of correctness (Duval \& Wicklund, 1972) or fixed reference values (Carver \& Scheier, 1981) implied that standards were immutable. A second factor involves the methods used in self-awareness research. Participants are typically led to focus on themselves continuously throughout the study. Self-focus increases self-attribution (Duval \& Silvia, in press; Duval \& Wicklund, 1973), so the continuous selffocus promoted an attribution of the discrepancy to self. Unless attention is diverted toward the standard after failure, thus promoting attribution to the standard (Duval \& Lalwani, 1999), self-attribution for failure and hence changing self toward standards will occur.

Clinical psychology, however, has long known about the importance of attribution in changing standards. Some therapies focus on the irrational and unattainable standards that are implicated in many disorders (Beck, 1967; Wells \& Matthews, 1994). Rational--emotive therapy, for example, focuses on problems caused by irrational beliefs, such as believing that all others should always like oneself. Irrational beliefs are essentially standards that can never be achieved (cf. Carver \& Ganellen, 1983). Therapy involves helping people recognize that their unreasonably high standards are responsible for their unhappiness. This attribution in turn leads to a moderation of the standards and an increase in well-being. 
Despite the continual progress in self-awareness research, many theoretical issues remain ambiguous and unresolved. The more trenchant and controversial issues are discussed following. Although we have no firm answers here, we hope that by formulating the problems we can provide a guide for future inquiry.

\section{Origin, Organization, and Affective Implications of Standards}

The nature of internalized standards, considered here very broadly, has never been fully explained by psychology. There is little agreement concerning the circumstances of internalization. Classic psychoanalytic positions argued that standards were internalized under conditions of threat or uncertainty, such as when the superego is formed to reduce castration anxiety (Freud, 1920, 1923). Later ego psychologists, in contrast, assumed that the internalization of ideas and objects could be motivated by the reality principle in the service of conflict-free ego activities. People might internalize a standard because it facilitates efficient adaptation to the environment (e.g., White, 1963, 1972). A similar view is found in personal construct psychology.

Representations that are maximally predictive, regardless of valence, are appropriated; standards that lose their predictive power are eventually rejected (Kelly, 1955). Also to contribute to the lack of consensus, symbolic interactionists reject the necessity of threat, uncertainty, or accuracy altogether. Internalization of the reference group's standards is simply what people do when they are born into a microculture of socially created, shared, and transmitted meanings and symbols (Mead, 1934; Shibutani, 1961).

Models of the structural organization of standards are equally diverse. Some approaches assume a disheveled and loosely structured system, or at least do not explicitly posit organizing principles. This was the position of the original OSA theory, as well as of some of the ego psychology positions (White, 1963). Other positions assume shared organizing categories. Freud (1923), for example, assumed that the superego has two subsystems. The ego ideal contains desirable, virtuous, and perfectionist ego states. The conscience, in contrast, consists of representations of morally bad and undesirable ego states. This categorization presumably obtains across persons. A similar shared structure comes from self-discrepancy theory (Higgins, 1987); it bifurcates standards into ideals, which represent attractive possible self-states, and oughts, which represent appropriate states that self should have. Internalized ideals and oughts can also be divided according to standpoints on the self, particularly one's own standards or the ideals and oughts that others hold for the self (Higgins, 1987). Less molar examples include distinctions between public--private standards (Scheier \& Carver, 1983) and personal-social standards (Gibbons \& Wright, 1983). Yet others assume that the organizing categories are idiosyncratic. Kelly (1955) assumed that standards and other constructs were organized by unique superordinate constructs. Carver and Scheier (1998) argued for a more tightly organized system with standards configured in an elaborate, yet personally unique, hierarchy. Also, Shibutani (1961) proposed that standards were organized according to the respective reference group from which they were internalized.

Given the lack of consensus concerning the origins and organization of standards, the widespread disagreement over the affective implications of standards is not surprising. Several theories assume a simple positive-negative affective reaction that corresponds to more or less successful or rapid attempts to meet standards (Carver \& Scheier, 1998; Duval \& Wicklund, 1972). Other theories assume that different emotions arise from different discrepancies; a structure of emotional response is essentially mapped onto a structure of standards. Self-discrepancy theory (Higgins, 1987) is the most elaborate example of this approach. Discrepancies between an existing self-state and one's own ideals lead to dejection, whereas discrepancies between self and another's ideals lead to shame and embarrassment. When self is discrepant from one's own oughts, agitated affect ensues, whereas discrepancies between self and another's oughts leads to agitation and anxiety. Freud (1923), in contrast, assumed that both facets of the superego involved the same emotional response. When action is harmonious with the ego ideal, "the ego experiences feelings of pride" (Hall, 1954, p. 47). Failure to meet the ego ideal leads to feelings of shame, guilt, and inferiority. Likewise, "the tension between the demands of conscience and the actual performances of the ego is experienced as a sense of guilt" (Freud, 1923, p. 33). Others were not concerned with this issue (Kelly, 1955; Shibutani, 1961; White, 1963). 
So what conclusions can be drawn from this conflict? Not very many--there is not much to say except that much more attention needs to be given to this issue. In some ways these issues are "academic"; the previously mentioned theories invoke distinctions that are often highly technical. Yet in other ways these issues are deeply significant and foundational. After all, the problem of how people acquire ideas and representations and how these representations become valenced cuts across many areas of psychology, from identity development to prejudice reduction to religious conversion. An understanding of the internalization and organization of standards would have implications for areas far beyond the boundaries of objective self-awareness theory; this should be a primary task for future work.

\section{Selecting a Standard of Comparison}

A related problem concerns precisely how standards participate in self-evaluation processes. People have a lot of internalized standards. At least some standards must contradict each other in some situations. Honesty, for example, might be the best policy, yet battles are also averted through diplomacy. When new parents ask for a person's opinion regarding their ugly newborn, the standards of "be honest" and "avoid shaming friends" call for incompatible actions. Modesty is important, yet so is self-assertion and putting one's best foot forward. Which standard is used? Also, if adhering to one standard creates a discrepancy with a second standard, how do people negotiate the conflict?

OSA doesn't specify how a specific standard is selected for the self-to-standard comparison process.

Experimental studies avoid the problem by experimentally inducing a standard or by preselecting people for existing standards. Making the study tilt toward a certain standard is critical for testing the basic propositions of the theory, but it obscures the problem of standard selectivity. Past theory has simply assumed that situations contain cues that make one standard particularly salient. This may be true of simple contexts, but complex social situations surely make conflicting or diverging standards salient. Salience alone, then, does not solve the problem.

We currently have no firm solution. A field-theoretic orientation (Lewin, 1935), however, suggests some possibilities for future research. The instance of conflicting standards can be represented as an approach-approach conflict between two attractive regions. Conflict could be resolved by changing the valence of one of the regions. One standard could be made more or less important, thus changing the positivity of its valence and its consequent behavioral attractiveness. One standard could also be devalued or rejected--this is another way of thinking about the changing standards research discussed earlier (Duval \& Lalwani, 1999). By derogating a standard, it becomes less positively valenced and thus reduces the magnitude of the approach--approach conflict. These two possibilities--manipulating a standard's importance or valence--seem like promising areas for future research. We suspect that they will be supported because analogous findings--trivialization and the spreading of alternatives--have been found in cognitive dissonance research (Simon, Greenberg, \& Brehm, 1995; Wicklund \& Brehm, 1976).

A second possibility comes from action identification research (Vallacher \& Wegner, 1987), which is concerned with how people construe the same activity in different ways and the psychological consequences of different construals. One finding from this research is that people will view activity at a more concrete level if they are having problems performing the act. A conflict between standards certainly creates problems for discrepancy reduction. People might resolve the conflict by identifying their action at a more concrete level. This could potentially dissolve the conflict that exists at the broader level.

Consider, for example, a young man flirting with a woman. On one hand, he wants to appear impressive, competent, and generally worthy of one of the woman's Friday nights. On the other hand, he wants to appear modest, self-deprecating, and down-to-earth. These two standards will pull his actions in different directions and thus lead to problems performing the flirting activity. This standard conflict can be resolved by identifying the action at a lower level, such as moving from "being modest versus being assertive" to the less abstract "trying to get a date." Neither being a bit self-aggrandizing nor appearing modest is inconsistent with this new 
identification. In short, reconstruing the activity can supplant the conflicting standards with a new standard that is harmonious with ongoing activity. This is another promising avenue for future research.

\section{Functions of Affect in Self-Awareness Processes}

A third unresolved theoretical issue concerns the role of affect in self-awareness processes. Three general positions can be found. The first position, which is found in the original OSA theory (Duval \& Wicklund, 1972; Wicklund, 1975), assumes that the negative affect created by self-standard discrepancies has a motivational character. Consistent with its roots in gestalt views of motivation (Heider, 1960) and past consistency theories (Festinger, 1957; Heider, 1958), the proposition of the model is that affect provided the energy and the incentive for the restoration of the preferred state of self-standard identity. A second position assumes that affect has an informational or monitoring function (Carver \& Scheier, 1998). This view has its roots in cybernetic models of how action is controlled by online performance feedback (Miller et al., 1960). Affect serves this feedback function by indexing the velocity of goal progress. A third position is simply the view that discrepancies create affect but that the affect has no stated implications for later discrepancy reduction. In self-discrepancy theory, for example, it is unclear what functions anxiety, dejection, and so on serve in subsequent regulation (Higgins, 1987).

As before, the conflict within the broader area of inquiry implicates self-awareness theory. Emotion psychologists have always argued over the functions of affect. The prevailing position, proposed by Darwin (1872/1998) and promulgated primarily by Tomkins $(1962,1981,1991)$ and his students (Izard, 1971, 1977), is that emotions motivate action. This broad notion is not very controversial: Ekman and Davidson (1994) listed "emotions have motivational properties" as one of the few things that "most students of emotion agree about" (p. 412), but it is not always clear what is meant by "motivation." Some theories assume that the motivating character of affect lies in its prioritizing effects (Oatley \& Johnson-Laird, 1996; Tomkins, 1991). By adding incentive to one of many possible actions, emotions enable important adaptive activity in the face of other attractive possibilities. Other theories assume that emotions provide the energetic "oomph" toward a single action (Frijda, 1986). Emotions, in this view, are motivational because they direct and energize single adaptive actions. In addition, of course, there are theories that eschew motivation and instead argue for informational functions of affect. Carver and Scheier (1990,1998), for example, argued that affect is the output function of a system that monitors that rate of progress toward a goal. Affect thus indicates rather than motivates the intensity of activity. Batson, Shaw, and Oleson (1992) also argued that emotions are capable of amplifying motivational states, but they primarily give information about what is valued and preferred.

From this variety of perspectives, we are inclined toward the motivational position. There are certainly merits to the informational position advanced by Carver and Scheier $(1990,1998)$. Affect processes dovetail seamlessly into their broader model of feedback and action control and can thus provide an internally consistent account of how emotions organize activity. Yet a considerable body of data supports the general view that emotions motivate activity, particularly the appearance of emotions before advanced cognition in infancy (Izard, 1978), the obvious motivating effects of emotions in cognitively simple animals (Darwin, 1872/1998), the links between emotional processes and incentive systems in the brain (Panksepp, 1998), and broad relations between emotions and autonomic activity (Levenson, 1992). With regard to self-awareness processes more specifically, there is a lot of support for the gestalt model of consistency motivation (Heider, 1960). The motivating character of cognitive dissonance, for example, is pretty well established (Elliot \& Devine, 1994; Wicklund \& Brehm, 1976). It seems reasonable that essentially similar self-standard consistency processes would have similar dynamic underpinnings. We thus view the informational model as serving a useful heuristic function within the cybernetic metaphor and the motivation model as more reflective of actual affect dynamics.

\section{Self-Awareness and Other Aspects of Thought}

\section{Automatic and Controlled Activity}

Contemporary research commonly distinguishes different forms of thinking and acting, such as automatic versus controlled (Shiffrin \& Schneider, 1977), mindless and mindful (Langer, 1978), and so forth. This distinction is central to recent theories of automatic activity (e.g., Bargh \& Chartrand, 1999), which assume that 
behavior will be automatically guided by primed stereotypes and associations unless it is interrupted or otherwise regulated (Macrae \& Johnston, 1998). Dijksterhuis and van Knippenberg (2000) extended this reasoning to objective self-awareness. They suggested that focusing attention on the self can break automatic links between priming and behavior because highly self-aware people consciously consider different action possibilities instead automatically following primed associations. Two studies found that persons low in selffocus showed the usual automaticity effects--for example, writing more garrulous essays after a "politician prime"--whereas highly self-aware persons were unaffected by priming manipulations (Dijksterhuis \& van Knippenberg, 2000).

Yet we suggest that the correspondence between automatic versus controlled processing and subjective versus objective self-awareness is not as tidy as some might think. Although much activity in the subjective state is probably habitual and conducted without concern for one's standards, the objective state itself displays important aspects of automaticity. Objective self-awareness is not a dispassionate, reflective state in which people appraise the situation and then select a course of action. Focusing attention on the self is assumed to initiate an automatic process that compares the self against one or more standards. By automatic we mean that the comparison process occurs spontaneously and is not easily controlled or regulated by conscious, deliberate thought processes. Indeed, these comparisons need not occur consciously or involve standards that are themselves accessible to conscious awareness. This comparison process is assumed to follow gestalt consistency principles (Heider, 1960). The self-organizing nature of the comparison system is thus inherent in the system and might potentially be impervious to conscious circumvention (cf. Koffka, 1935; Wertheimer, 1945).

Research on self-awareness in clinical disorders shows how impenetrable this automatic evaluation process can be. Self-awareness is implicated in a broad range of clinical problems (see Wells \& Matthews, 1994), many of which involve unfavorable self-evaluations. People suffering from depression and social anxiety, for example, often experience automatic negative thoughts about the self. Intensive therapy is needed to regulate these spontaneous evaluations and attributions. It is noteworthy that successful therapies cope with this problem by changing the unrealistic standards involved in the comparison process or by regulating the self-evaluation after the fact, as in reframing (e.g., Beck, 1967; Wells \& Matthews, 1994). Actually inhibiting or preventing the comparison process appears to be difficult.

We suggest that different forms of information processing are relevant to objective self-awareness, but that the processes described by OSA theory do not neatly assimilate into these categories. OSA might derail automatic effects on behavior, though not because it invokes a conscious, reflective mode of processing. Instead, it changes what is important to people by diverting attention to an unresolved discrepancy and arousing motivation to do something about it (Silvia \& Gendolla, in press). Certainly the automatic effects observed thus far have been emotionally neutral and self-irrelevant--and hence less important--than typical self-standard discrepancies. We have yet to see, for instance, automatic rejection of one's ambitions or interpersonal ostracization as a result of priming. Yet the intersections to date are intriguing, and more thought should be devoted to how automaticity and self-standard comparison interlock.

\section{Thought Regulation and Suppression}

The ironic process theory of mental control (Wegner, 1994) is also worth intersecting with self-awareness. Wegner proposed that the intention to produce any particular state of mind activates a monitoring process. This process is designed to determine the extent of failure to achieve the desired state of mind. For example, monitoring processes activated by the intention to suppress unpleasant thoughts search for instances in which suppression has failed. Such processes would then be concerned with precisely those instances in which undesired thoughts, in this case unpleasant thoughts, are present in the mental system. Indications of failed mental control initiate an operating process. This process attempts to generate the intended state of mind by searching for mental content that is consistent with the desired state. In the case of intended suppression of unpleasant thoughts, for example, this process searches for pleasant mental content. 
Ironic process theory also specifies when the content located by the operating process or material revealed by the monitoring process dominates conscious awareness. When mental capacity required by the operating process is adequate, material found by that search program will dominate conscious awareness. If the suppression of unpleasant thoughts is the intended goal and mental capacity is sufficient, for instance, the pleasant thoughts found by the operating process search will dominate consciousness. Alternately, when mental capacity is suboptimal for the operating process, material found by the monitoring will dominate consciousness. In the case of desired suppression of unpleasant thoughts, for example, a lack of adequate mental capacity would lead to domination of conscious awareness by precisely those thoughts the person is trying to suppress. Wegner (1994) also specified conditions that diminish the mental capacity required to enable optimal operating process functioning. These include cognitive load, insufficient time to achieve intended mental control goals, stress, and so forth. Under conditions in which the value of any of these variables is high, the person's consciousness will be concerned with thoughts revealed by the monitoring rather than the operating system.

Thus, under high cognitive load, for example, a person who intends to achieve a positive mood state will actually experience thoughts related to its opposite and become sad (Wegner, Erber, \& Zanakos, 1993). Ironic process theory is particularly pertinent to mental processes that might follow the awareness of selfstandard discrepancies. It seems reasonable to assume that awareness of self as deficient relative to what it ought to be could provoke a desire to suppress that unpleasant ideation. However, as Wegner (1994) noted, negative self-evaluation and the negative affect associated with such an appraisal could, in and of itself, represent a cognitive load. Thus, given Wegner's (1994) notion of a self-loading ironic system, negative selfevaluations induced through self-awareness could undermine the operating process's search for positive thoughts about self. This would lead ironically to increased awareness of thoughts found by the monitoring process regarding self as being deficient and undesirable. Such an increase in unpleasant self-relevant ideation could further elevate cognitive load and from ironic process theory further increase the extent to which the content of awareness is focused on negative aspects of self. Because in Wegner's (1994) opinion this situation represents the operation of a positive feedback loop, the processes leading to increasingly negative selfevaluation could escalate to the point where a mental obsession with self as being negative could occur. Future research should certainly investigate this possibility as well as the broader links between self-evaluation and the dynamics postulated in ironic process theory.

\section{Summary}

Objective self-awareness theory has taken many twists and turns during its 30-year history. We have reviewed some of the most recent developments and outlined some of the continuing problems. Most of the progress addresses the directionality of activity. The original theory said very little about how one way of dealing with a discrepancy was selected from the many coping possibilities--people either reduced the discrepancy or avoided self-focus. The theory now posits two primary moderators. The first is rate of progress relative to discrepancy size (Carver et al., 1979a, 1979b; Duval et al., 1992). The second is the person's attributions for the cause of the discrepancy. People should act on whatever element is seen as responsible for the problem, be it self, one's standards, another person, or some other perceived cause. These two variables are also intertwined--an insufficient rate leads to avoidance and, if self is the most plausible cause, defensive attributions to external causes. The theory is now better equipped to specify why discrepancy reduction takes one path rather than another. Standards have also lost their privileged position within the theory. Self-evaluation is no longer viewed as the relentless pursuit of the correct state. OSA theory now regards standards as being malleable and subject to change in the service of consistency restoration.

Although progress has been made on the relations between the concepts of the theory, some questions still remain about the nature of the concepts themselves. Self-awareness research has never devoted much attention to standards. Past work typically considered standards downstream of the internalization process. As a result, not much is known about how standards are internalized in the first place. The experimental necessity of isolating single standards also obscured the problems associated with the multiplicity of standards. When standards conflict, or at least suggest diverging actions, it is not clear what people will do. Also, affect has always been assumed to have a motivating function in discrepancy reduction, although there is surprisingly little 
research that actually tests this. We hope that these and other uncertainties will stimulate another 30 years of intriguing research on the dynamics of self-awareness.

\section{Notes}

1 Our review is solely concerned with situational self-awareness. Dispositional self-focus, known as selfconsciousness (Fenigstein, Scheier, \& Buss, 1975), has come under psychometric scrutiny of late (e.g., Anderson, Bohon, \& Berrigan, 1996; Chang, 1998; Watson, Morris, Ramsey, Hickman, \& Waddell, 1996). Deficiencies in the scales have led researchers to argue that new conceptual models and resulting scales are needed (Creed \& Funder, 1998, 1999; Silvia, 1999; Trapnell \& Campbell, 1999). Some have already proposed alternative scales and conceptualizations (Trapnell \& Campbell, 1999); others are currently developing alternative views of dispositional self-awareness (e.g., Creed \& Funder, 1999; McKenzie \& Hoyle, 1999). It would be premature to discuss this nascent literature--indeed, much of the work is unpublished or still in progress. A review of dispositional approaches will thus have to wait until enough data are available to evaluate these new directions.

\section{References}

Anderson, E. M., Bohon, L. M., \& Berrigan, L. P. (1996). Factor structure of the private self-consciousness scale. Journal of Personality Assessment, 66, 144-152.

Arkin, R. M., \& Duval, T. S. (1975). Focus of attention and causal attribution of actors and observers. Journal of Experimental Social Psychology, 11, 427-438.

Arndt, J., Greenberg, J., Simon, L., Pyszczynski, T., \& Solomon, S. (1998). Terror management and selfawareness: Evidence that mortality salience provokes avoidance of the self-focused state. Personality and Social Psychology Bulletin, 24, 1216-1227.

Bandura, A. (1977). Self-efficacy: Toward a unifying theory of behavioral change. Psychological Review, 84, 191-215.

Bargh, J. A., \& Chartrand, T. L. (1999). The unbearable automaticity of being. American Psychologist, 54, 462479.

Batson, C. D., Kobrynowicz, D., Dinnerstein, J. L., Kampf, H. C., \& Wilson, A. D. (1997). In a very different voice: Unmasking moral hypocrisy. Journal of Personality and Social Psychology, 72, 1335-1348.

Batson, C. D., Shaw, L. L., \& Oleson, K. C. (1992). Differentiating affect, mood, and emotion: Toward functionally based conceptual distinctions. In M. S. Clark (Ed.), Review of personality and social psychology (Vol. 13, pp. 294-326). Newbury Park, CA: Sage.

Batson, C. D., Thompson, E. R., Seuferling, G., Whitney, H., \& Strongman, J. A. (1999). Moral hypocrisy: Appearing moral to oneself without being so. Journal of Personality and Social Psychology, 77, 525-537.

Beck, A. T. (1967). Depression. New York: Hoeber.

Carver, C. S. (1975). Physical aggression as a function of objective self-awareness and attitudes toward punishment. Journal of Experimental Social Psychology, 11, 510-519.

Carver, C. S., Blaney, P. H., \& Scheier, M. F. (1979a). Focus of attention, chronic expectancy, and responses to a feared stimulus. Journal of Personality and Social Psychology, 37, 1186-1195.

Carver, C. S., Blaney, P. H., \& Scheier, M. F. (1979b). Reassertion and giving up: The interactive role of selfdirected attention and outcome expectancy. Journal of Personality and Social Psychology, 37, 1859-1870.

Carver, C. S., \& Ganellen, R. J. (1983). Depression and components of self-punitiveness: High standards, selfcriticism, and overgeneralization. Journal of Abnormal Psychology, 92, 330-337.

Carver, C. S., \& Scheier, M. F. (1981). Attention and self-regulation: A control-theory approach to human behavior. New York: Springer.

Carver, C. S., \& Scheier, M. F. (1990). Origins and functions of positive and negative affect: A control-process view. Psychological Review, 97, 19-35.

Carver, C. S., \& Scheier, M. F. (1998). On the self-regulation of behavior. New York: Cambridge University Press.

Chang, L. (1998). Factor interpretations of the self-consciousness scale. Personality and Individual Differences, 24, 635-640. 
Cohen, J. L., Dowling, N., Bishop, G., \& Maney, W. J. (1985). Causal attributions: Effects of self-focused attentiveness and self-esteem feedback. Personality and Social Psychology Bulletin, 11, 369-378.

Cooley, C. H. (1902). Human nature and the social order. New York: Scribners.

Creed, A. T., \& Funder, D. C. (1998). The two faces of private self-consciousness: Self report, peer-report, and behavioral correlates. European Journal of Personality, 12, 411-431.

Creed, A. T., \& Funder, D. C. (1999). Shining the light on private self-consciousness: A response to Silvia (1999). European Journal of Personality, 13, 539-542.

Dana, E. R., Lalwani, N., \& Duval, T. S. (1997). Objective self-awareness and focus of attention following awareness of self-standard discrepancies: Changing self or changing standards of correctness. Journal of Social and Clinical Psychology, 16, 359-380.

Darwin, C. (1998). The expression of the emotions in man and animals (3rd ed.). New York: Oxford University Press. (Original work published 1872)

Diener, E. (1979). Deindividuation, self-awareness, and disinhibition. Journal of Personality and Social Psychology, 37, 1160-1171.

Dijksterhuis, A., \& van Knippenberg, A. (2000). Behavioral indecision: Effects of self-focus on automatic behavior. Social Cognition, 18, 55-74.

Duval, T. S. (1976). Conformity on a visual task as a function of personal novelty on attitudinal dimensions and being reminded of object status of self. Journal of Experimental Social Psychology, 12, 87-98.

Duval, T. S., \& Duval, V. H. (1983). Consistency and cognition. Hillsdale, NJ: Lawrence Erlbaum Associates, Inc.

Duval, T. S., \& Duval, V. H. (1987). Level of perceived coping ability and attribution for negative events. Journal of Social and Clinical Psychology, 5, 452-468.

Duval, T. S., Duval, V. H., \& Mulilis, J. P. (1992). Effects of self-focus, discrepancy between self and standard, and outcome expectancy favorability on the tendency to match self to standard or to withdraw. Journal of Personality and Social Psychology, 62, 340-348.

Duval, T. S., \& Lalwani, N. (1999). Objective self-awareness and causal attributions for self-standard discrepancies: Changing self or changing standards of correctness. Personality and Social Psychology Bulletin, 25, 1220-1229.

Duval, T. S., \& Silvia, P. J. (in press). Self-awareness, probability of improvement, and the self-serving bias. Journal of Personality and Social Psychology.

Duval, T. S., \& Wicklund, R. A. (1972). A theory of objective self-awareness. New York: Academic.

Duval, T. S., \& Wicklund, R. A. (1973). Effects of objective self-awareness on attributions of causality. Journal of Experimental Social Psychology, 9, 17-31.

Ekman, P., \& Davidson, R. J. (1994). Affective science: A research agenda. In P. Ekman \& R. J. Davidson (Eds.), The nature of emotion (pp. 411-430). New York: Oxford University Press.

Elliot, A. J., \& Devine, P. G. (1994). On the motivational nature of cognitive dissonance: Dissonance as psychological discomfort. Journal of Personality and Social Psychology, 67, 382-394.

Federoff, N. A., \& Harvey, J. A. (1976). Focus of attention, self-esteem and attribution of causality. Journal of Research in Personality, 10, 336-345.

Fenigstein, A., Scheier, M. F., \& Buss, A. H. (1975). Public and private self-consciousness: Assessment and theory. Journal of Consulting and Clinical Psychology, 43, 522-527.

Festinger, L. (1957). A theory of cognitive dissonance. Stanford, CA: Stanford University Press.

Freud, S. (1920). Beyond the pleasure principle. New York: Norton.

Freud, S. (1923). The ego and the id. New York: Norton. Frijda, N. H. (1986). The emotions. Cambridge, England: Cambridge University Press.

Froming, W. J., Nasby, W., \& McManus, J. (1998). Prosocial self-schemas, self-awareness, and children's prosocial behavior. Journal of Personality and Social Psychology, 75, 766-777.

Gibbons, F. X. (1978). Sexual standards and reactions to pornography: Enhancing behavioral consistency through self-focused attention. Journal of Personality and Social Psychology, 36, 976-987.

Gibbons, F. X. (1983). Self-attention and self-report: The "veridicality" hypothesis. Journal of Personality, 51, 517-542. 
Gibbons, F. X. (1990). Self-attention and behavior: A review and theoretical update. Advances in Experimental Social Psychology, 23, 249-303.

Gibbons, F. X., \& Wicklund, R. A. (1976). Selective exposure to self. Journal of Research in Personality, 10, 98-106.

Gibbons, F. X., \& Wright, R. A. (1983). Self-focused attention and reactions to conflicting standards. Journal of Research in Personality, 17, 263-273.

Greenberg, J., \& Musham, C. (1981). Avoiding and seeking self-focused attention. Journal of Research in Personality, 15, 191-200.

Hall, C. S. (1954). A primer of Freudian psychology. New York: World.

Heider, F. (1944). Social perception and phenomenal causality. Psychological Review, 51, 358-374.

Heider, F. (1958). The psychology of interpersonal relations. New York: Wiley.

Heider, F. (1960). The gestalt theory of motivation. In M. R. Jones (Ed.), Nebraska symposium on motivation (Vol. 8, pp. 145-172). Lincoln: University of Nebraska Press.

Higgins, E. T. (1987). Self-discrepancy: A theory relating self and affect. Psychological Review, 94, 319-340.

Hull, J. G. (1981). A self-awareness model of the causes and consequences of alcohol consumption. Journal of Abnormal Psychology, 90, 586-600.

Ickes, W. J., Wicklund, R. A., \& Ferris, C. B. (1973). Objective self awareness and self esteem. Journal of Experimental Social Psychology, 9, 202-219.

Ingram, R. E. (1990). Self-focused attention in clinical disorders: Review and a conceptual model.

Psychological Bulletin, 107, 156-176.

Izard, C. E. (1971). The face of emotion. New York: Appleton-Century-Crofts. Izard, C. E. (1977). Human emotions. New York: Plenum.

Izard, C. E. (1978). On the development of emotions and emotion-cognition relationships in infancy. In M.

Lewis \& L. A. Rosenblum (Eds.), The development of affect (pp. 389-413). New York: Plenum.

James, W. (1890). The principles of psychology. New York: Henry Holt.

Kelly, G. A. (1955). The psychology of personal constructs: Vol. 1. A theory of personality. New York: Norton.

Koffka, K. (1935). Principles of gestalt psychology. New York: Harcourt-Brace.

Langer, E. (1978). Rethinking the role of thought in social interaction. In J. H. Harvey, W. J. Ickes, \& R. F.

Kidd (Eds.), New directions in attribution research (Vol. 2, pp. 35-58). Hillsdale, NJ: Lawrence Erlbaum

Associates, Inc.

Lazarus, R. S. (1966). Psychological stress and the coping process. New York: McGraw-Hill.

Levenson, R. W. (1992). Autonomic nervous system differences among emotions. Psychological Science, 3, 23 27.

Lewin, K. (1935). A dynamic theory of personality. New York: McGraw-Hill.

Macrae, C. N., Bodenhausen, G. V., \& Milne, A. B. (1998). Saying no to unwanted thoughts: Self-focus and the regulation of mental life. Journal of Personality and Social Psychology, 74, 578-589.

Macrae, C. N., \& Johnston, L. (1998). Help, I need somebody: Automatic action and inaction. Social Cognition, 16, 400-417.

May, R. (1967). Psychology and the human dilemma. New York: Van Nostrand Reinhold.

McDonald, P. J. (1980). Reactions to objective self-awareness. Journal of Research in Personality, 14, $250-260$.

McKenzie, K. S., \& Hoyle, R. H. (1999,May). The self-absorption scale. Paper presented at the 71st Annual Meeting of the Midwestern Psychological Association, Chicago.

Mead, G. H. (1934). Mind, self and society. Chicago: University of Chicago Press.

Miller, G. A., Galantner, E., \& Pribram, K. H. (1960). Plans and the structure of behavior. New York: Holt, Rinehart \& Winston.

Mullen, B. (1983). Operationalizing the effect of the group on the individual: A self-attention perspective. Journal of Experimental Social Psychology, 19, 295-322.

Oatley, K., \& Johnson-Laird, P. N. (1996). The communicative theory of emotions: Empirical tests, mental models, and implications for social interaction. In L. L. Martin \& A. Tesser (Eds.), Striving and feeling (pp. 363-393). Mahwah, NJ: Lawrence Erlbaum Associates, Inc.

Panksepp, J. (1998). Affective neuroscience: The foundations of human and animal emotions. New York: Oxford University Press. 
Pryor, J. B., \& Kriss, M. (1977). The cognitive dynamics of salience in the attribution process. Journal of Personality and Social Psychology, 35, 49-55.

Pyszczynski, T., Hamilton, J. C., Greenberg, J., \& Becker, S. E. (1991). Self-awareness and psychological dysfunction. In C. R. Snyder \& D. R. Forsyth (Eds.), Handbook of social and clinical psychology: The health perspective (pp. 138-157). New York: Pergamon.

Rudner, R. S. (1966). Philosophy of social science. Englewood Cliffs, NJ: Prentice Hall.

Scheier, M. F., \& Carver, C. S. (1977). Self-focused attention and the experience of emotion: Attraction, repulsion, elation, and depression. Journal of Personality and Social Psychology, 35, 625-636.

Scheier, M. F., \& Carver, C. S. (1983). Private and public aspects of the self. In L. Wheeler (Ed.), Review of personality and social psychology (Vol. 2, pp. 189-216). Beverly Hills, CA: Sage.

Shibutani, T. (1961). Society and personality: An interactionist approach to social psychology. Englewood Cliffs, NJ: Prentice Hall.

Shiffrin, R. M., \& Schneider, W. (1977). Controlled and automatic information processing: II. Perceptual learning, automatic attending, and a general theory. Psychological Review, 84, 127-190.

Silvia, P. J. (1999). Explaining personality or explaining variance? A comment on Creed and Funder (1998). European Journal of Personality, 13, 533-538.

Silvia, P. J. (2001). Nothing or the opposite: Intersecting terror management and objective self-awareness. European Journal of Personality, 15, 73-82.

Silvia, P. J., \& Duval, T. S. (in press). Predicting the interpersonal targets of self-serving attributions. Journal of Experimental Social Psychology.

Silvia, P. J., \& Gendolla, G. H. E. (in press). On introspection and self-perception: Does self-focused attention enable accurate self-knowledge? Review of General Psychology.

Simon, L., Greenberg, J., \& Brehm, J. (1995). Trivialization: The forgotten mode of dissonance reduction.

Journal of Personality and Social Psychology, 68, 247-260.

Taylor, S. E., \& Fiske, S. T. (1978). Salience, attention, and attribution: Top of the head phenomena. Advances in Experimental Social Psychology, 11, 249-288.

Tomkins, S. S. (1962). Affect, imagery, consciousness: Vol. 1. The positive affects. New York: Springer. Tomkins, S. S. (1981). The quest for primary motives: Biography and autobiography of an idea. Journal of Personality and Social Psychology, 41, 306-329.

Tomkins, S. S. (1991). Affect, imagery, consciousness: Vol. 3. The negative affects: Anger and fear. New York: Springer.

Trapnell, P. D., \& Campbell, J. D. (1999). Private self-consciousness and the five-factor model of personality: Distinguishing minination from reflection. Journal of Personality and Social Psychology, 76, 284-304.

Vallacher, R. R., \& Wegner, D. M. (1987). What do people think they're doing? Action identification and human behavior. Psychological Review, 94, 3-15.

Watson, P. J., Morris, R. J., Ramsey, A., Hickman, S. E., \& Waddell, M. G. (1996). Further contrasts between self-reflectiveness and internal state awareness factors of private self-consciousness. Journal of Psychology, 130, 183-192.

Wegner, D. M. (1994). Ironic processes of mental control. Psychological Review, 101, 34-52.

Wegner, D. M., Erber, R., \& Zanakos, S. (1993). Ironic processes in the mental control of mood and moodrelated thought. Journal of Personality and Social Psychology, 65, 1093-1104.

Wells, A., \& Matthews, G. (1994). Attention and emotion: A clinical perspective. Hillsdale, NJ: Lawrence Erlbaum Associates, Inc.

Wertheimer, M. (1945). Productive thinking. New York: Harper.

White, R. W. (1963). Ego and reality in psychoanalytic theory: A proposal regarding independent ego energies (Psychological Issues Series, Volume 3(3), Monograph No. 11). New York: International Universities. White, R. W. (1972). The enterprise of living: Growth and organization in personality. New York: Holt, Rinehart \& Winston.

Wicklund, R. A. (1975). Objective self-awareness. Advances in Experimental Social Psychology, 8, $233-275$. Wicklund, R. A., \& Brehm, J. W. (1976). Perspectives on cognitive dissonance. Hillsdale, NJ: Lawrence Erlbaum Associates, Inc. 